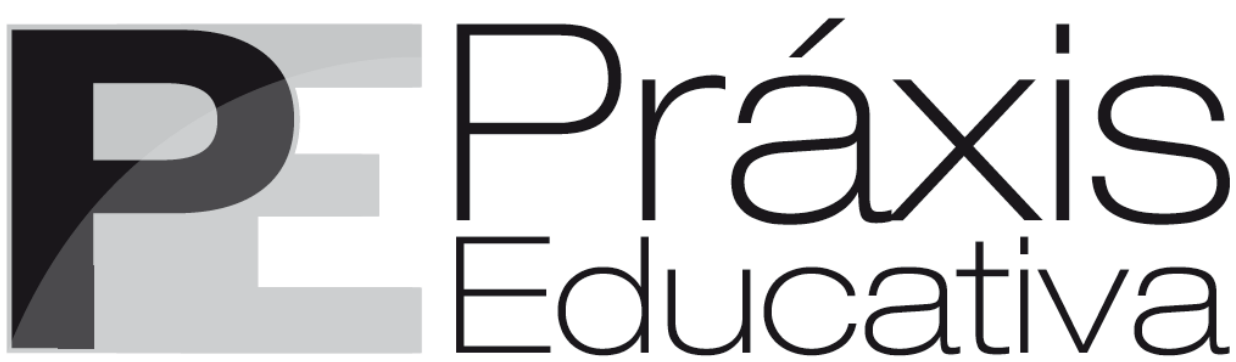

ISSN 1809-4309 (Versão online) DOI: 10.5212/PraxEduc.v.12i2.0017

\title{
UNESCO. Diretrizes em Educação Física de qualidade: para gestores de políticas. Brasília: UNESCO, 2015. 86 p.*
}

\author{
Eduard Angelo Bendrath ${ }^{* *}$ \\ Andréia Paula Basei*** \\ Fagner Sene Rodrigues ${ }^{* * * *}$
}

O livro Diretrizes em Educação Física de Qualidade (EFQ) para gestores de políticas, publicado em 2015, é fruto do trabalho da Organização das Nações Unidas para a Educação, a Ciência e a Cultura (UNESCO) que, em decorrência da realidade observada, da importância e das experiências vivenciadas na área da educação física e esportes em diferentes contextos, tem por objetivo avançar no debate e nas ações para garantir o direito ao acesso à Educação Física de Qualidade (EFQ). Debate este que, atualmente, envolve e necessita de ações governamentais e do apoio da comunidade internacional. A obra foi escrita com base em três princípios fundamentais - igualdade, salvaguarda e participação significativa - para orientar e apoiar o desenvolvimento de políticas; levantar recursos e desenvolver práticas inclusivas em contextos sociais diversos.

A leitura do livro, desde a sua apresentação, ressalta a importância da educação física e do desenvolvimento de políticas que terão impacto positivo nos diferentes aspectos da formação da juventude. Para tal, o livro aborda, de maneira contextualizada, ações coerentes a serem desenvolvidas pelos gestores para a implementação de políticas na área, apresentando-se estruturado da seguinte forma: Apresentação; Resumo executivo: um chamado para a ação; Glossário dos termos-chave; Parte 1 - Introdução; Parte 2 - Construindo um ambiente inclusivo de política em EFQ; Parte 3 - Política de EFQ em ação e; Parte 4 - Colocar os princípios em prática.

$\mathrm{Na}$ apresentação da obra é feita, de forma lógica e coerente, uma introdução e contextualização sobre os assuntos que serão abordados nas partes seguintes, principalmente no sentido de expor as finalidades para as quais as diretrizes foram elaboradas, bem como alertar os gestores das políticas sobre a importância da implementação destas e de justificar os motivos para os investimentos feitos na área. São também apresentados os termos-chave utilizados a fim de esclarecer ao leitor o posicionamento teórico adotado. Percebe-se certo cuidado na elaboração e escrita do livro, desde o seu início, com relação a uma linguagem clara e objetiva, mas que

\footnotetext{
* Disponível em: <http://unesdoc.unesco.org/images/0023/002319/231963POR.pdf>. Tradução de "Quality Physical Education (QPE) Guidelines for Policy-Makers", publicado em 2015 pela UNESCO, em Paris.

** Professor da Universidade Estadual de Maringá (UEM). E-mail: <bendrath@gmail.com>.

*** Professora da Universidade Estadual de Maringá (UEM). E-mail: <andreiabasei@yahoo.com.br>.

**** Graduado em Educação Física - Universidade Estadual de Maringá (UEM). E-mail: <guinho_pfc@hotmail.com>.
} 
UNESCO. Diretrizes em Educação Física de qualidade: para gestores de políticas. Brasília...

também possui uma fundamentação teórica de valor científico e, acima de tudo, clareza nas suas possibilidades de aplicabilidade prática, tendo em vista o público ao qual se destina.

A Parte 1 - Introdução, apresenta uma importante contextualização histórica sobre o compromisso da UNESCO com a educação física e esportes desde 1952, tendo se consagrado em 1978, com a Carta Internacional da Educação Física, bem como de outras organizações internacionais (Intergovernmental Committee for Physical Education and Sport - CIGEPS; North Western Countries Physical Education Association - NWCPEA) preocupadas com as políticas na área. Todavia, é ressaltado que a implementação destas políticas é bastante diversificada devido às condições peculiares dos países e/ou regiões em que se desenvolvem, fato que ainda a torna inconsistente.

Num segundo momento, são apresentadas justificativas sobre a importância da oferta de uma EFQ, tanto no que diz respeito à formação de cidadãos capazes de agir de acordo com as demandas emergentes do cenário sociocultural e econômico da atualidade, quanto aos aspectos relacionados à saúde e a melhoria da qualidade de vida. Finalizando esta parte, fica explícito como as diretrizes propostas podem auxiliar os gestores de políticas, tendo como fundamento principal a flexibilidade, ou seja, é enfatizado que para se construir uma política de EFQ é preciso conhecer as características e demandas locais. Para isso, o material disponibiliza um instrumento para avaliação e implementação de ações em diferentes contextos educacionais, sejam eles formais ou não formais.

$\mathrm{Na}$ Parte 2 - Construindo um ambiente inclusivo de política em EFQ - são expostos pela UNESCO os passos principais para se desenvolver um ambiente de política em EFQ inclusiva. Estes são considerados como principal mecanismo para superar as desigualdades estruturais. Para isso, ao ressaltar a importância de políticas que impulsionem o engajamento em atividades físicas e esportes para além do âmbito escolar e que promovam e protejam os direitos humanos, a obra traz ainda, de forma clara e objetiva 10 passos para a construção de um ambiente de política inclusiva em EFQ, cuja finalidade é encorajar os Estados-membros a desenvolver suas próprias visões da EFQ com uma abordagem multissetorial da sociedade, além de ressaltar a necessidade de instalações e estruturas adequadas e profissionais qualificados. Na sequência, é observada a importância de os indivíduos serem instruídos fisicamente, do significado de ser um indivíduo instruído fisicamente e da necessidade de os gestores apoiaram e priorizarem esta questão por meio do desenvolvimento de políticas e programas. Seguindo seu objetivo de ser um guia teóricoprático, o livro traz exemplos de alguns projetos desenvolvidos em nível mundial, destacando impactos positivos alcançados no desenvolvimento da Educação Física, especialmente em contextos de emergência.

A Parte 3 - Políticas de Educação Física de Qualidade em Ação, remete à questão da garantia de uma abordagem inclusiva e de construção de uma visão geral da área, tomando como princípio metodologias que atendam os parâmetros da EFQ. Sobre essa questão, a UNESCO adota uma série de indicativos alinhados aos preceitos gerais da Organização no que tange ao seu entendimento sobre o campo da educação, referendados pelas conferências de Jomtien (1990) e Dakar (2000) e que devem ser considerados dentro da gestão da qualidade educacional no campo da educação física. Na proposta de diretrizes para uma abordagem inclusiva, a UNESCO elenca três tópicos: Igualdade de Gênero, Deficiência e Grupos Minoritários.

No tópico sobre a igualdade de gênero são priorizados os princípios da garantia dessa condição e a necessidade de os planejadores educacionais oferecerem condições de acesso a uma educação de qualidade. Partindo desse pressuposto a Organização faz um chamado aos seus Estados-membros para envidarem esforços para assegurar oportunidades iguais de participação ativa de meninas na educação física e nos esportes. Esta questão é enfatizada com a apresentação

Práxis Educativa, Ponta Grossa, v. 12, n. 2, p. 591-594, maio/ago. 2017 Disponível em: <http://www.revistas2.uepg.br/index.php/praxiseducativa> 
de um estudo de caso sobre empoderamento de mais de 3.000 meninas quenianas com idades entre 05 e 24 anos, cujo objetivo foi fornecer suporte para que permaneçam ou retornem ao ambiente escolar, de forma a possibilitar-lhes o acesso e os benefícios de se frequentar a escola.

Ao abordar o tema deficiência, o texto ampara-se na Convenção sobre os Direitos das Pessoas com Deficiências (Convention on the Rights of Persons with Disabilities - CRPD) que obriga os Estados-membros a garantir que crianças com deficiências tenham acesso igualitário na participação em jogos, recreação e esportes, incluindo-as, portanto, no sistema escolar. Discute-se também o papel da formação de professores em educação física e sua relação com o princípio da inclusão, caminhando para a apresentação de evidências a partir de um estudo de caso na Irlanda, onde professores da área foram capacitados a desenvolver, entre outros aspectos, a autoeficácia em suas habilidades para defender e garantir a inclusão de pessoas com deficiência em suas turmas.

A discussão do princípio da abordagem inclusiva se encerra com o tópico sobre grupos minoritários, no qual se argumenta que a educação física e o esporte podem ser vistos como meio de inclusão social de populações marginalizadas. $O$ texto defende atividades bem planejadas que incorporem os valores centrais da educação física e do esporte - autodisciplina, respeito, jogo limpo, trabalho em equipe e adesão a regras mutuamente acordadas - e que ajudem os indivíduos a desenvolver os valores e as habilidades de comunicação necessárias para prevenir e solucionar conflitos em suas próprias vidas. Como referência, é apresentado um estudo de caso desenvolvido na Nova Zelândia, fundamentado em um modelo curricular cultural, indicando que uma visão curricular da educação física que englobe os valores sociais e culturais de uma determinada região podem ser passíveis de sucesso.

O tópico seguinte da obra aborda a questão da construção de uma visão de EFQ amparada em cinco pontos centrais: flexibilidade curricular, parcerias comunitárias, monitoramento e garantia de qualidade, formação, suprimento e desenvolvimento de professores, instalações, equipamentos e recursos.

No quesito flexibilidade curricular é discutida a necessidade de os currículos maximizarem suas potencialidades com objetivo direto de contribuir para o processo ensino-aprendizagem dos alunos. Os modelos tradicionais desenvolvidos atualmente são criticados, apontando-se a necessidade de construção de currículos flexíveis e adaptáveis. A argumentação é referendada pela apresentação de um estudo de caso nos Estados Unidos, com mais de 300.000 jovens de 5 a 18 anos, cujo foco foi redefinir os currículos de educação física, pautando os jovens como direcionadores da ação a partir das experiências e interesses individuais.

Com relação às parcerias comunitárias, o livro remete ao conceito de que o papel da educação física deve ser incluir resultados educacionais mais amplos, para toda a vida. Discute-se a carga horária limitada da educação física nos currículos escolares, as discussões da Organização Mundial da Saúde (OMS) e do Parlamento Europeu, bem como, incentiva-se o estabelecimento de parcerias entre as escola e comunidade. É apresentado um estudo de caso realizado na Venezuela e Cuba, com mais de 9 milhões de pessoas, onde tal parceria elevou os níveis de participação em atividades físicas contribuindo para a melhoria da qualidade de vida.

Como outro ponto central, o monitoramento e garantia da qualidade na educação física são discutidos a partir da elaboração de relatórios imparciais que sirvam para a tomada de decisões das autoridades públicas. Sugere-se a criação de um órgão autônomo responsável por toda a coordenação do processo de monitoramento e avaliação das ações de implementação e oferta de EFQ, conforme realizado na Inglaterra e País de Gales, onde 150 escolas foram 
UNESCO. Diretrizes em Educação Física de qualidade: para gestores de políticas. Brasília...

avaliadas no período de 2008 a 2012 no que tange à qualidade do ensino e currículo, desempenho escolar e gestão e condução da educação física.

No ponto formação, suprimento e desenvolvimento de professores, a UNESCO constrói um discurso voltado ao intrínseco relacionamento entre qualidade da educação física e a formação de professores. Afirma-se a necessária melhoria dos processos de formação inicial e continuada, tendo como foco central a atuação desses professores nas escolas primárias e anos iniciais da educação básica. É sugerida a criação de um órgão específico, responsável por coordenar e oferecer um marco de ação para o desenvolvimento profissional, direcionado para o aprofundamento dos conhecimentos e para o desenvolvimento de novas habilidades. Também é apresentado um estudo de caso envolvendo a Coréia do Sul, Filipinas, Mongólia e Indonésia, no qual 120 professores participaram de um processo de capacitação que envolveu o intercâmbio entre os países com o intuito de construir uma rede de relacionamentos e know-how de novas práticas pedagógicas.

Com relação às questões de instalações, equipamentos e recursos como forma de garantir o amplo acesso a uma política de EFQ, a UNESCO reforça o argumento em favor de um ambiente de aprendizagem favorável, o que, invariavelmente, coloca sobre os gestores públicos a necessidade de garantir um compromisso financeiro para com uma proposta de EFQ. Para assegurar o lugar da educação física no currículo escolar, a oferta não deve ser marginalizada em favor de outras disciplinas e/ou eventos que requerem recursos. Para a gestão das ações, deve ser assegurado, por parte dos governos, o uso de materiais pedagógicos adequados e, na possível falta de infraestrutura, equipamentos e materiais, o estabelecimento de parcerias com organizações esportivas comunitárias pode minimizar os problemas. Exemplo disso é o estudo de caso envolvendo mais de 305.000 jovens e 2.037 professores em 717 escolas no México, Guatemala, Nicarágua, Costa Rica, Panamá e Colômbia, cujo foco foi o estabelecimento de uma macroparceria com a fundação Coca-Cola para a aquisição de equipamentos com o intuito de promover atividades educacionais e recreativas voltadas ao bem estar físico de alunos e professores.

O capítulo se encerra mencionando as ações de defesa da EFQ como política pública dos governos, responsabilizando os órgãos governamentais e conselhos locais de educação física na atuação para garantir a defesa e a legitimação de uma EFQ. Os governos devem se responsabilizar pela garantia de que a educação física tenha o mesmo status de outras disciplinas, conscientizando diretores, professores de outras disciplinas, familiares e a comunidade como um todo sobre sua importância bem como, para reduzir a atual discrepância entre as prioridades do governo e dos praticantes.

$\mathrm{Na}$ quarta e última parte do livro - Colocar os Princípios em Prática - são apresentados três grupos de documentos como anexos que fazem referência a: 1) Marcos de referência para a EFQ; 2) Marcos de ação relativos à oferta de EFQ inclusiva e, 3) Bibliografia. Tais anexos serviriam de suporte para gestores iniciarem o processo de tomada de decisão frente à implantação de políticas de EFQ amparadas por instrumentos orientadores da UNESCO.

Concluímos que esta obra, com originalidade e relevância, é uma referência para gestores de políticas em educação física e esportes que buscam um guia teórico-prático sobre a implementação de políticas, com exemplos de experiências concretas e instrumentos que possibilitam não só a avaliação das demandas, mas também oferecem diretrizes sobre padrões mínimos para oferta da imprescindível formação de profissionais com perfil para atender as exigências da EFQ. 